\title{
Ten Tips for Day Trippers
}

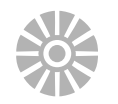

I. Always telephone first. Places may be closed unexpectedly, or they may change their public hours at any moment.

2. Check websites when they are available. However, when it comes to hours and prices, they may not be as up to date as the recorded message. Websites are fine for "seeing the place" first and for travel directions.

3. Take along a full-sized map, drinks, snacks, flashlight, extra jacket, and other things you may need.

4. Do not show up during the last half-hour. Places that require guided tours often refuse admittance an hour before closing.

5. Use coupons and "two-fers." Most amusement parks have marketing arrangements with companies for two-for-one admissions with a soda can, coupon, or other promotion. Also check for discount coupons in brochures, flyers, and newspapers.

6.Go on free days or off-season. State parks, for example, are free off-season.

7. Buy season tickets. This makes sense if you live within close range. Or become a member of a local museum, garden, or zoo.

8. Use your corporate or organizational clout. When companies support institutions, their employees may get a free corporate day or a discount. Members of AAA or AARP often get discounts. Check with your town's recreation department; it may have discount tickets for attractions and events.

9. "Suggested Donation" means just that. If you are visiting for a short time or have a large family with you, you do not have to pay the full suggested donation, but you should pay something.

Io. Watch out for extras, such as parking fees and sales tax. Always take along more money than you think you will need. 
